\title{
New Insights into Emotion Valence and Loyalty Intentions in Relational Exchanges
}

\author{
Sally McKechnie \\ Nottingham University Business School \\ sally.mckechnie@nottingham.ac.uk \\ Prithwiraj Nath \\ Leeds Beckett University \\ P.Nath@leedsbeckett.ac.uk \\ Jiyao Xun \\ Alliance Manchester Business School \\ jiyao.xun@manchester.ac.uk
}

Correspondence regarding this article should be sent to:

Sally McKechnie, Nottingham University Business School, UK

(sally.mckechnie@nottingham.ac.uk) 


\title{
New Insights into Emotion Valence and Loyalty Intentions in Relational Exchanges
}

\begin{abstract}
This research examines how emotion valence and future intentions arising from relational exchanges with a service firm depend on a consumer's level of goal attainment and locus of causality (firm versus self) of relational outcomes. Drawing on the theories of goal-directed behaviour and agency of causation, this study hypothesizes that levels of goal attainment and locus of causality influence the generation of positive emotions (gratitude), negative emotions (grudge and guilt), relational mediators (trust and commitment) and subsequent future intentions to remain loyal to the firm. Based on a controlled experiment with 284 subjects in a consumer-determined relationship setting, the research finds that emotion valence and future loyalty intentions are contingent upon the fulfilment of relational objectives of individual consumers and the agency of causation for the outcome of the relational exchanges. In doing so, this study delineates the conditioning mechanism that directs how emotion valence influences behavioural intentions. The study contributes to the consumer behaviour and services marketing literatures on consumption-based emotions and has significant practice implications for relational behaviours.
\end{abstract}

Keywords: Emotion Valence; Goal Attainment; Agency; Relational Exchange; Gratitude; Grudge; Guilt. 


\section{INTRODUCTION}

Scholars who have devoted attention to the influence of emotions on consumer behavioural intentions have suggested that this often depends on the valence of the stimuli and the level of affective disconfirmation that consumers face in the consumption process (Aurier \& Guintcheva, 2014; Phillips \& Baumgartner, 2002; Ruth, Brunel, \& Otnes, 2004). A stimulus can be appetitive leading to positive emotions or aversive leading to negative emotions, whereas the level of disconfirmation is based on consumer expectations. This proposition suggests that when a service firm makes certain service delivery promises that generate consumer expectations and a consumer faces an aversive stimulus such as a service failure, he or she will have negative feelings toward the firm irrespective of the level of relational goal attainment that the consumer achieves based on their expectations and who is to blame for the service failure (i.e. the firm versus self). This assumes homogeneity of consumer behaviour in terms of the effect of a stimulus on emotion development and expectation realisation irrespective of individual goal pursuit.

However, to the contrary, the generation of emotion valence is often context-specific (Lerner \& Keltner, 2000; Richins, 1997) and differs between consumers based on their relational goal attainment with the service firm (Bagozzi, 1995; Bagozzi, Dholakia, \& Gopinath, 2007) and the trigger of the causation of events (Roseman, 1991; Smith \& Ellsworth, 1985). This calls for research in understanding the following: how a consumer's self-determined relational goal attainment with a service firm influences emotion valence triggered by relational exchanges with the firm; how emotion valence, in turn, influences behavioral intentions; and how the perceived agency of causation of relational exchange outcomes (i.e. the firm or self) influences the relationship between consumer's relational goal attainment and emotion valence. 
The purpose of this article is to explore these areas by focusing on two theoretical strands: the goal-directed model (Dholakia and Bagozzi, 2002; Bagozzi et al., 2003) and the theory of agency of causation (Roseman, 1991; Smith \& Ellsworth, 1985). According to the goal-directed model the consumer's effort, engagement in relational activities, expectations from the firm and their behavior depend on the level of goal attainment that the consumer is able to achieve by maintaining a relationship with the firm. Therefore, a central proposition of this theory is that stimuli cannot influence emotion valence unilaterally but depend on the levels of relational goal attainment of individual consumers. On the other hand, the theory of agency of causation proposes that goal (in)congruence cannot be the only decider of emotion valence because it is the perceived agency causing (in)congruence which plays a major contingency role.

The present study proposes a theoretical framework (see Figure 1) where varied levels of goal attainment lead to the positive emotion of gratitude (Palmatier, Jarvis, Bechkoff, \& Kardes, 2009), the negative emotions of grudge and guilt (Bunker \& Ball, 2008; Basil, Ridgway, \& Basil, 2006) and the relational mediators of trust and commitment (Morgan \& Hunt, 1994); these emotions and relational mediators in turn influence future intentions (Garbarino \& Johnson, 1999); and the relationship between goal attainment and emotions and relational mediators is moderated by the agency of causation (Roseman, 1991). The study uses a controlled experimental scenario where 284 subjects participated in a study that involved a service failure situation with a hypothetical insurance firm. The findings contribute to the consumer behavior and service marketing literatures by offering novel insights into the influence of emotion valence and future loyalty intentions in relational exchanges. They also provide direction to service firms for developing tactical relational approaches to build and manage consumer emotions and strengthen loyalty intentions. 
The paper proceeds as follows. In the next section extant literature is reviewed and hypotheses are developed. The research methodology is then explained and the analysis of the results presented. Finally, the discussion, implications and limitations are presented and a conclusion is drawn.

\section{CONCEPTUAL DEVELOPMENT}

\section{Goal-directed behaviour as an antecedent to consumption-based emotions and} relational behaviours

Consumer behaviour tends to be goal-directed: in other words, the consumer is motivated to purposefully and consciously attain a particular goal (Bagozzi, Dholakia, \& Basuroy, 2003; Dholakia, 2006; Richetin, Perugini, Adjali, \& Hurling, 2008). Psychological research contends that individuals cognitively appraise consumption on the consistency of consequences with their expectations (Lazarus, 1991; Soscia, 2007). The level of goal attainment (or "goal realisation") is defined as the attainment of the goal chosen by an individual on his or her account (Bagozzi et al., 2003). This is a subjectively-felt congruence between one's prior expectation and the exact current goal attainment, which occurs when a customer cognitively assesses the consequence of such goal pursuit.

Unlike in repetitive or habitual consumption activities, where there is a comparatively low level of customer engagement and low intrinsic motivation to achieving a desired goal target or expected goal outcome (Bagozzi et al., 2003, Dholakia, 2006), the motivation for cognitive appraisal following goal attainment or goal failure is strengthened in goal-directed behaviour because of high personal involvement and heightened attention in customer self-determined relational engagement with a service provider. This paper argues that a consumer's future loyalty intentions with a service 
firm hinge on his/her perceived level of goal attainment which impacts consumptionbased emotions.

\section{Relational mediators}

Emotions provide the fuel for bringing about effective action (Taylor \& Pham, 1996). Generally, positive (euphoric) emotions lead to continuous goal pursuit whilst negative (dysphoric) emotions result in avoiding undesired outcomes of recent goal failures (Oatley \& Johnson-Laird, 1987). In the relationship marketing literature, commonly referred relational mediators are by nature emotions. The most cited and relevant ones to customer self-determined behaviour are therefore considered.

Customer gratitude is a strong and momentary-felt emotion elicited where the customer perceives a high level of goal outcome typically associated with a benefit received (Emmons \& McCullough, 2004). This construct serves to delineate the inner feelings of a goal-directed customer, who successfully achieves a goal and can identify the role of the firm in facilitating this positive outcome. Thus feelings of gratefulness, thankfulness or appreciation are instigated towards the seller. Algoe, Haidt, \& Gable (2008) contend that gratitude plays an important role in initiating and sustaining the relationship-building cycle between the recipient and the benefactor and eventually enhances relationship quality over time. Similarly, Palmatier et al. (2009) argue that a customer feeling gratitude (and therefore a beneficiary) re-earns a balance by giving or repaying something back to the benefactor. Therefore, for a goaldirected customer who is in a self-determined relationship with a service firm, customer gratitude arising from a favorable goal outcome means that the customer appreciates and recognizes a firm's reliability and integrity in delivering such a result. Thus, gratitude increases the buyer's confidence in predicting the firm's future actions 
(Doney \& Cannon, 1997) and leads to repurchase intentions (Bock, Folse, \& Black, 2016).

In the same vein, a customer who is feeling gratitude also develops trust and commitment towards the exchanging firm, which means that a customer becomes more inclined to desire a long-lasting relationship with the firm. Trust is defined as confidence in an exchange partner's reliability and integrity (Doney \& Cannon, 1997), whereas commitment is a lasting desire to maintain a valued relationship (Morgan \& Hunt, 1994). The present study argues that for a self-determined customer, feeling gratitude toward a firm is more likely to develop such desire and therefore commitment.

Since commitment-trust theory (Morgan \& Hunt, 1994) maintains that there is a strong bond between customer trust and commitment towards an exchanging partner, this paper suggests that for a self-determined customer the causal link between customer trust and commitment remains valid specifically when a highly selfmotivated customer would appreciate and recognize a firm's reliability and integrity. Trust would consequently translate into a lasting desire to maintain such a valued relationship. Thus, we argue that a self-determined customer will have strong future intentions with a firm and customer trust and commitment will have been established.

Overall, this set of positive relational mediators, i.e. gratitude, trust, commitment enhances future intentions via a strengthened customer reciprocal inclination benefited from such goal attainment. We do not include other customer emotions such as happiness, pride or satisfaction to be part of positive relational mediators because literature defines them as too mild to be sufficient in determining consumer future intentions (Soscia, 2007). 
Still, we are equally interested in understanding the impact of negative emotions such as customer guilt on a goal-directed customer's future intentions with a firm because consumption experiences are not always positive and satisfying. By definition, guilt relates to a negative valence appraisal towards perceptions of the self and projects self-image as socially undesirable (Agrawal \& Duhachek, 2010). It represents a deep reflection on goal failure, where one perceives one's own mistakes as causing the outcome rather than the firm. This is in line with intrinsic motivation theory, where consumers who feel guilty for a failed self-initiated relationship with a firm are more likely to engage in prosocial behaviour that starts a relational payback to the firm. The behaviour of guilty consumers, however, shall be different from the disengagement behaviour of customers who are holding a grudge; rather they eliminate any undesirable images by paying the seller back by way of re-patronage, purchase behaviour or simply making positive referrals. Palmatier et al. (2009) explain this effect as the reciprocal nature of relational exchanges. According to these theories, it is predicted that customers feeling guilty will increase their future loyalty behaviour or patronage to pay back such "failure of duty" (Ferguson, 1999) and alleviate psychological burdens brought by internal attribution to self. Although very few empirical studies have investigated the role of guilt in relational exchanges, we suggest it may shed light in explaining how customer goal-directed behaviour affects future loyalty intentions.

Finally, grudge is a strong reactive emotion in the opposite direction to gratitude. As an intense feeling of resentfulness, sometimes associated with retaliation intentions and behavioural avoidance (Bunker \& Ball, 2008; Grégoire, Tripp, \& Legoux, 2009), it is chosen to reflect the immediacy of negative consumption-based emotions that arise when the stimulus event results in a low level of goal attainment perceived to be 
caused by the firm. A firm causing an unfavourable goal outcome is likely to deter a self-determined customer from engaging in any future relational exchanges with the firm.

Based on these arguments it is proposed that:

H1: A high level of goal attainment (as compared to a low level) will increase consumers' perceptions of (a) gratitude (b) trust (c) commitment but decrease consumers' perceptions of (d) grudge (e) guilt.

H2: Consumers' perceptions of (a) gratitude (b) trust and (c) commitment are positively related to consumers' future loyalty intentions.

H3: Consumers' perceptions of (a) grudge and (b) guilt are negatively related to consumers' future loyalty intentions.

\section{Agency of causation}

How service customers cope with emotions is important because coping has been theorized to influence post-purchase behaviours such as repurchase, word-of-mouth and complaining (Yi \& Baumgartner, 2004). However, in psychological theories consumers have another type of cognitive appraisal of consumption relating to the perceived causation of events (Soscia, 2007), whereby a consumer's active evaluations of the causation of an event are typically attributed to impersonal circumstances, another person or the self. Depending on the agency of this causation (Roseman, 1991; Smith \& Ellsworth, 1985), a specific set of emotions arises such as guilt, anger or sadness.

According to Novemsky \& Dhar (2005) successful goal attainment enhances an individual's future ongoing pursuits of the target goal at a higher level so that the 
pursuit of goal attainment is paramount. Should goal conflict subsequently arise and potentially jeopardise goal attainment, then a person's self-control mechanism is activated to resolve conflict in favour of prioritising goal attainment (Zhang, Huang, \& Broniarczyk, 2010)

Extant studies on goal congruence (see Bagozzi, Gopinath, \& Nyer, 1999; Roseman, Antoniou \& Jose, 1996) are limited to a general appraisal toward a generic product/service category or purchase. Since such a narrow definition results in the elicitation of mild forms of emotions (e.g. happiness, pride and satisfaction), Soscia (2007) argues that this approach is insufficient in determining consumer future intentions. Furthermore, Garbarino \& Johnson (1999) found that satisfaction serves only as a hygiene factor which is not enough to foster high-relational customers into trusted and committed ones. Instead, trust and commitment are the key mediators between customer goal (in)congruence and future intentions. Thus, emotions that are high in intrinsic motivation evoke high arousal and intensity (Mehrabian \& Russell, 1974). Since these emotions are capable of triggering future intentions, it is proposed that:

H4: The positive association between a high level of goal attainment (as compared to a low level) and consumers' perceptions of (a) gratitude (b) trust and (c) commitment will be higher when the agency of causation is the firm rather than self.

H5: The negative association between a high level of goal attainment (as compared to a low level) and consumers' perceptions of (a) grudge and (b) guilt will be lower when the agency of causation is the firm rather than self. 
Figure 1 presents a framework to explore the hypothesized relationships between goal attainment, agency of causation and consumption based emotions.

$$
\text { [Insert Figure } 1 \text { about here] }
$$

\section{METHOD}

\section{Participants and context}

Students of a large British university participated in this study through an online experiment. The researchers used the university database to send online flyers inviting students to participate with a chance to win a prize draw. Students represent a homogeneous body with a similar demographic profile (such as age, education, social status) and are therefore suitable for any experiment-based studies. The context chosen was that of a customer making a claim against an insurance firm offering a 24hour replacement service for laptop computers as part of its gadget insurance policy. This firm was fictitious to remove any effects of past experience or brand recognition and the policy was typical (i.e. based upon a contract to protect gadgets for a fixed time period of cover, by the end of which the customer would either renew for the same period or seek cover from another supplier) Pre-tests were conducted and revealed that the chosen context of claiming a 24-hour laptop replacement was highly familiar to students as the underlying motive for taking out a gadget policy is to minimize any potential disruption to their daily lives caused by a damaged or stolen laptop to their daily lives. Thus consumers' motives are instrumental rather than consummatory since they are undertaken to achieve other goals (Pham, 1998). 900 students were invited to participate in the online experiment and there were 352 
respondents, however only 284 of the questionnaires were fully completed and useable (i.e. final valid response rate $31.5 \%$ ).

The sample was $53 \%$ male, mostly in the age group between 20 and 24 years, and mainly postgraduate students. Around $80 \%$ of them had prior experience of purchasing insurance online.

\section{Experimental design and procedure}

To explore the effects of customer goal attainment on the emotional outcomes and the moderating role of agency of causation, this study used a 2 (goal attainment: high versus low) by 2 (agency of causation: firm versus self) between-subjects experimental design. A successful (unsuccessful) insurance claim led to high (low) goal attainment, whereas if the efforts made towards processing the claim was facilitated and enhanced by an employee of the firm (customer), then the agency of causation was firm (self). The chosen context (i.e. insurance claim for a 24 hour laptop replacement) provided a scenario where a high personal stake was involved in the outcome, the relationship was customer self-determined rather than firm-induced, there was realistic level of uncertainty in goal attainment and the success or failure of goal attainment was either firm- or self-driven. The scenario statements were developed in three stages. First, the researchers carefully reviewed prior scenario designs for eliciting customer gratitude (Palmatier et al., 2009) and customer grudge (Bunker \& Ball, 2008). Second, the researchers went through consumer emotional reactions (i.e. positive and negative) from online postings on two insurance-related websites to identify a list of service requirements. Third, the researchers interviewed managers of five firms that provide laptop insurance about the proposed scenarios. Once the scenarios had been finalized (see Appendix A1 for an illustrative scenario for gratitude that represents high goal attainment and firm-agency), the participants 
were introduced to the study on a dedicated website and asked how they would feel if they suddenly lost their laptop before an important assignment/examination. The purpose of this question was to increase their involvement with the study (following Palmatier et al., 2009) before they were randomly allocated to one of the four scenarios using an online software.

The sample sizes for the scenarios were as follows: Control Scenario (high goal attainment $\mathrm{x}$ self-agency) $n=77$; Gratitude Scenario (high goal attainment $\mathrm{x}$ firmagency) $n=56$ ); Guilt Scenario (low goal attainment $x$ self-agency) $n=66$; and Grudge Scenario (low goal attainment $x$ firm-agency) $n=85$. This resulted in 141 respondents perceiving a firm agency of causation, while 143 respondents perceived a self-agency of causation. Following Wagner, Hennig-Thurau, \& Rudolph (2009), the participants responded to two realism checks (Cronbach's alpha=0.92): "I could imagine an actual laptop insurance company doing the things described in the situation earlier," and "I believe that the described situation could happen in real life" with $1=$ strongly disagree, $5=$ strongly agree. Results showed that the scenarios reflected a sufficient level of realism (mean composite score $=4.74, \mathrm{SD}=1.94$ ).

\section{Manipulation check}

The study used a sample of 29 students from a large British university for the manipulation check. To test the levels of goal attainment (high versus low), the researchers asked the respondents to read the chosen scenario and indicate the extent to which they agreed with the statement "I was able to achieve my goal described" on a scale from 1 (strongly disagree) to 5 (strongly agree). A t-test revealed significant differences between the scenarios (high goal attainment: mean=4.43; low goal attainment: mean $=2.08, \mathrm{t}=5.73, \mathrm{p}<0.01$ ). Next, to test the agency of causation (self or firm) following Shang, Reed \& Croson (2008), the researchers asked the respondents 
to indicate the extent to which they agreed with the statement "The success/failure of achieving my goal is largely because of the firm's or my own efforts/mistakes" on a scale from 1 (the firm) to 5 (myself). A t-test revealed significant differences (selfagency: mean $=4.08$; firm-agency: mean $=3.00, \mathrm{t}=2.69, \mathrm{p}<.05)$.

\section{Measures}

The study adapted 24 items to measure the 7 constructs: goal attainment ( $\mathrm{Ng} \&$ Tsang, 2000; Bagozzi et al., 2003), gratitude (Palmatier et al., 2009), grudge (Bunker \& Ball, 2008), guilt (Basil et al., 2006), trust and commitment (De Wulf, OdekerkenSchröder, \& Iacobucci, 2001), and future intentions (Hennig-Thurau, Groth, Paul, \& Gremler, 2006; Garbarino and Johnson, 1999) (see Appendix A2). All the items were measured using a 7 point scale ( $1=$ strongly disagree, $7=$ strongly agree). In addition, the study collected data on demographics (age, gender) and previous insurance purchase experience (yes or no) as control variables.

\section{ANALYSIS AND RESULTS}

\section{Construct validity}

The study used confirmatory factor analysis (CFA) to test the measurement properties of the latent constructs. After making some modifications based on items loading on more than one construct or a very low loading on its own construct, 7 items in the scale were removed from further consideration (as indicated in Appendix A2). The study tested the model on the criteria of overall fit, reliability, convergent, and discriminant validity. CFA results showed a good overall fit of the model with $\chi^{2}$ $(146)=209.32(p<0.01), \chi^{2} /$ d.f. $=1.43$. The values of root mean square error of approximation RMSEA $=0.04$, goodness of fit index GFI $=0.94$, and comparative fit index CFI $=0.95$ were within the acceptable range (Hu \& Bentler, 1999). The study 
tested the reliability of the constructs by using Cronbach's alpha (with minimum as 0.79 ) and composite reliability (with minimum as 0.88 ). The standardized loadings of all items on their intended latent constructs were significant indicating convergent validity (see Table 1). The average variance extracted (AVE) of all the constructs exceeded 0.5 (with minimum as 0.71 ) and the squared correlation between any two constructs was less than the AVE extracted by the constructs. This indicated discriminant validity of the model (Fornell \& Larcker, 1981). Therefore, the model was fit for subsequent analysis.

[Insert Table 1 about here]

To test the possibility of common method variance (CMV), the study used Harmon's one factor test where a single latent factor would account for all manifest variables (McFarlin \& Sweeney, 1992). A worse fit for the one-factor model would suggest that CMV does not pose a serious threat. The one factor model in this study had $\chi^{2}(166)=$ 263.21 compared to the measurement model $\chi^{2}(146)=209.32$. As the fit is considerably worse, so CMV does not pose a threat to our study.

\section{Differences in levels of emotions among customers with varying goal attainments}

The study first verifies the assumption that high (low) levels of goal attainment lead to higher positive (negative) emotions based on the theory of goal-directed behaviour. The research used median split to categorise consumers into high $(n=136)$ and low $(n=148)$ levels of goal attainment based on their self-reported goal attainment scores. Table 2 shows that the mean scores for the outcome constructs of trust, commitment and gratitude are significantly higher for the high goal attainment consumer group as compared to the low attainment group, whereas grudge and guilt are higher for the 
low goal attainment group. Except for guilt, all the other differences are statistically significant. Thus the assumption of varying degrees of emotional outcomes based on levels of goal attainment is supported.

[Insert Table 2 about here]

\section{Relationship between goal attainment, emotions, relational mediators and future intentions}

The study used LISREL to test the hypothesized relationships. The overall fit of the model is $\operatorname{good}\left(\chi^{2}(109)=224.25 ; \mathrm{p}<0.01 ; \mathrm{RMSEA}=0.06 ; \mathrm{NFI}=0.98 ; \mathrm{CFI}=0.98\right.$. Table 3 shows that the influence of goal attainment on gratitude $(\beta=0.95, p<0.01)$, trust $(\beta=0.99, \mathrm{p}<0.01)$, commitment $(\beta=0.92, \mathrm{p}<0.01)$, grudge $(\beta=-0.67, \mathrm{p}<0.01)$ and guilt $(\beta=-0.13, p<0.05)$. Therefore, as levels of goal attainment increase, there is an increase in consumer feelings of gratitude, trust and commitment but feelings of grudge and guilt decrease. This supports H1a-H1e. The influence of relational mediators on future intentions: gratitude $(\beta=0.13, \mathrm{p}<0.10)$, trust $(\beta=0.29, \mathrm{p}<0.05)$, commitment $(\beta=0.40, \mathrm{p}<0.05)$. This supports $\mathrm{H} 2 \mathrm{a}-\mathrm{H} 2 \mathrm{c}$. The influence of negative emotions on future intentions: grudge $(-0.20, \mathrm{p}<0.05)$ and guilt $(\beta=-0.03$, not significant). This supports H3a but does not support H3b.

[Insert Table 3 about here]

The moderating role of levels of goal attainment and agency of causation on emotions and relational mediators 
The study used a MANCOVA followed by univariate ANOVAs with five dependent variables: positive (gratitude) and negative (grudge and guilt) emotions, and relational mediators (trust and commitment); two independent variables: the levels of goal attainment (high $=1$ versus low $=0$ as determined by the median split of the composite goal attainment score) and agency of causation (firm $=0$ versus self $=1$ as manipulated in the experiment); and three control variables: age, gender and insurance purchase experience. However, the influence of the control variables was not significant and they were dropped from further analysis for model parsimony. The ANOVA results in Table 4 shows that interaction effect between goal attainment and agency of causation is significant on gratitude, trust, commitment, and grudge but not on guilt. An examination of the means (see Table 2 and Figure 2) shows that for high goal attainment customers when firm is the agency of causation leads to higher gratitude, trust, commitment as compared to when self is the agency of causation. This supports $\mathrm{H} 4 \mathrm{a}-4 \mathrm{c}$. On the other hand, for high goal attainment consumers when firm is the agency of causation leads to lower grudge as compared to when self is the agency of causation. This supports H4d. However, the study does not find support for H4e.

[Insert Table 4 about here]

[Insert Figure 2 about here]

\section{DISCUSSION}

This study attempts to close the gap in the customer self-determined relational approach literature by incorporating goal theory and attribution theory to shed light on emotion valence and future loyalty intentions arising from relational exchanges. The results indicate that the levels of goal attainment and agency of causation have a 
significant influence on how consumers develop emotion valence following relational exchanges, which in turn influence behavioural intentions. However, the study does not find a significant influence on the negative emotion of guilt. As emotions of opposite valence can co-occur (Aurier \& Guintcheva, 2014) in the consumption experience, the influence on guilt might have been overshadowed by another positive emotional construct. Still, another possible explanation is that an emotion of the same valence could co-occur such as shame, which has been found to be closely correlated with guilt for self-caused rather than other-caused wrongdoing (Schmader \& Lickel, 2006). Essentially shame refers to feeling bad about oneself as opposed to feeling bad about one's behavior.

\section{Theoretical Contributions}

First, this study introduces a self-determined relational framework drawing on goaldirected theory to explain how consumers develop both positive and negative emotions towards the service provider. Past research (such as Yim, Tse, \& Chan, 2008; Aurier \& Guintcheva, 2014) that has explored how emotion valence can influence buyer behaviour often ignores the origin of relational orientation (firm vs. self). This research fills this gap by quantifying how a self-determined customer's goal attainments and consequent emotions relate to their continued patronage of the firm. This is realized by placing the goal-directed model as an antecedent to a set of customer positive and negative emotions that are elicited at the end of customer goal pursuit.

Second, this study explains the moderating role of agency of causation in the selfdetermined emotion framework. When a firm is perceived to have caused an unfavorable customer goal outcome, it harms the customer-firm relationship much more than the level of positive impact when a firm causes a favorable goal outcome. 
This contributes to Dholakia's (2006:118) call for clarity about "the degree to which their [i.e. self-determined customers'] locus of causality is internal or external on their relational outcomes.”

\section{Practice Contributions}

First, managers need to invest in marketing programmes that foster customer intrinsic motivation in pursuing a goal with a firm. In the selected context of insurance, firms can invest in areas such as IT infrastructure for customer relationship management, employee training and empowerment for customer contact employees and claims personnel as well as customer education to facilitate positive relational exchange outcomes. For example, firms can offer a compensation voucher as a goodwill gesture to stop customers holding a grudge against them and switching supplier. Second, managers also require training to ensure they have a solid understanding of customer's specific and contingent goal requirements in order to successfully deliver the customer's intended outcomes with the firm perceived as the principal agent of well-received relational exchange outcomes.

\section{Limitations, future research and conclusion}

The study has a few limitations. First, generalizability of the results is restricted by the single service setting of a self-determined customer relationship with a fictitious insurance firm for a policy involving fewer interactions over its lifetime compared to service settings of a long term and complex nature such as healthcare. However, during a personal crisis when customers need support from their insurance firms, the nature of relational exchanges can become extremely critical and trigger intense emotional responses. Future research can explore other service contexts. Second, while it is preferable when testing hypotheses to ensure homogeneity in the subjects' 
characteristics, the student sample reduces external validity. Third, this study manipulated and tested the levels of goal attainment using an experimental approach to examine the effects of goal attainment and agency of causation on emotion valence and future intentions in time-pressured relational exchanges. Future work can pursue a longitudinal study with a real-life insurance firm to assess these effects with customers who have experienced varying levels of goal attainment in their interactions with the firm over time.

To conclude, this study contributes to existing knowledge by exploring the influence of goal-directed behaviour on emotion valence and how agency of causation moderates such a relationship. As a goal-directed behavior is highly emotional, the findings indicate that customers' positive and negative emotions and their interplays offer a set of underlying psychological mechanisms on how self-determined customers may enhance or reduce their future intentions with a firm. 


\section{Appendix A1: Measurement scale}

Constructs Measures

\section{Goal attainment}

(based on $\mathrm{Ng} \&$ Tsang, 2000;

Bagozzi et al., 2003)

\section{Gratitude}

(based on Palmatier et al., 2009)

Trust

(based on De Wulf et al., 2001)

Commitment

(based on De Wulf et al., 2001)

\section{Grudge}

(based on Bunker \& Ball, 2008)
GA1. I was able to achieve my goal described above

GA2. My goal pursuit outcome is (unfavourable -favourable)

GRA1. I feel grateful to Laptop Support

GRA2. I feel thankful to Laptop Support

GRA3. I feel appreciative to Laptop Support *

TRU1. Laptop Support gives me a feeling of trust

TRU2. I have trust in Laptop Support.

TRU3. Laptop Support is not trustworthy (R)*

COM1. I am willing "to go the extra mile" to remain a consumer of Laptop Support.

COM2. I have a desire to maintain this relationship with Laptop Support.

COM3. I view the relationship with Laptop Support as a long-term partnership.

GRU1. A reasonable person would find it hard to forgive Laptop Support's service.

GRU2. I would harbour a grudge against Laptop Support.

GRU3. If this firm ever came to mind, I would probably remember their treatment of me with some bitterness.

GRU4. It would be difficult for me to forget the problem I had with Laptop Support's service.*

GRU5. I would think poorly of Laptop Support's service for a long time.*

GRU6. It would be difficult to forgive Laptop Support for treating me this way.*

\section{Guilt}

GUI1. I would feel guilty if I did not achieve my goal.

(based on Basil et al., 2006),

GUI3. I would feel regretful if I did not make it in my goal pursuit 


\section{Future intentions}

(based on Hennig-Thurau, et al., 2006; Garbarino \& Johnson, 1999)
FI1. The next time I need the services of laptop insurance, I will choose Laptop Support.

FI2. I will not say positive things about this laptop insurance service provider to other people.*

FI3. I would likely to renew my contract with Laptop Support in the future.

FI4. I will recommend Laptop Support to someone who seeks my advice.*

Note: * items dropped due to low or multiple loading on more than one construct, $1=$ strongly disagree, $7=$ strongly agree 


\section{Appendix A2: Scenario for gratitude as an illustration used in the study}

\section{Scenario Descriptions}

Two months ago, you found your laptop's manufacturer warranty had expired. Laptop Support, a specialist laptop insurance company, promises a 24-hour laptop replacement if your laptop is stolen or lost. After carefully studying their quote, you signed up for a 2-year insurance contract with them. One afternoon six months later, you are packing for an overseas trip. Your flight departs in 24 hours, but that day your laptop is stolen. You immediately think of your insurance contract with Laptop Support and your right to claim for a 24-hour replacement laptop from them. If successful, you will get a brandnew replacement laptop within 24 hours and be able to catch your flight.

Your goal clearly is to claim a 24-hour replacement laptop from Laptop Support under your laptop insurance policy. You immediately fax Laptop Support to submit your claim. You are expecting a favourable outcome because you believe you are making a genuine claim. The 24-hour promise made by Laptop Support is critical, as you are leaving for your overseas trip in 24 hours.

Gratitude Laptop Support informs you that your claim was successful; however, your airline has just told you that the late afternoon flight check-in time will be an hour earlier because of tightened security checks. You immediately realize you are highly likely to miss Laptop Support's promise of a 24-hour replacement laptop delivery because the replacement delivery could arrive anytime within 24 hours by courier. Delaying your flight will definitely incur a penalty charge from the airline. You explain your dilemma to a Laptop Support claims advisor called 'Alex'. He delivers the replacement in person to your home straight after his work. When he arrives, you learn that he has done this voluntarily for you. You can now catch your flight as planned. 


\section{References}

Algoe, S. B., Haidt, J., \& Gable S. L. (2008). Beyond reciprocity: Gratitude and relationships in everyday life. Emotion, 8, 425-29.

Agrawal, N., \& Duhachek, A. (2010). Emotional compatibility and the effectiveness of antidrinking messages: A defensive processing perspective on shame and guilt. Journal of Marketing Research, 47, 263-273.

Aurier, P., \& Guintcheva, G. (2014). Using affect-expectations theory to explain the direction of the impact of the experiential emotions on satisfaction. Psychology \& Marketing, 31, 900-913.

Bagozzi, R. P., Dholakia, U. M., \& Basuroy, S. (2003). How effortful decisions get enacted: The motivating role of decision processes, desires, and anticipated emotions. Journal of Behavioural Decision Making, 16, 273-295. Bagozzi, R. P., Gopinath, M., \& Nyer, P. U. (1999). The role of emotions in marketing. Journal of the Academy of Marketing Science, 27, 184-206. Basil, D. Z., Ridgway, N. M., \& Basil, M. D. (2006). Guilt appeals: The mediating effect of responsibility. Psychology \& Marketing, 23, 1035-1054.

Bock, D. E., Folse, J. A. G., \& Black, W. C. (2016). When frontline employee behavior backfires: Distinguishing between customer gratitude and indebtedness and their impact on relational behaviors. Journal of Service Research, 19, 322-336. Bunker, M. P., \& Ball, D. (2008). Causes and consequences of grudge-holding in service relationships. Journal of Services Marketing, 22, 37-47.

De Wulf, K., Oderkerken-Schröder, G., \& Iacobucci, D. (2001). Investments in consumer relationships: a cross-country and cross-industry exploration. Journal of Marketing, 65, 33-50. 
Dholakia, U. M. (2006). How customer self-determination influences relational marketing outcomes: Evidence from longitudinal field studies. Journal of Marketing Research, 43, 109-120.

Dholakia, U. M. \& Bagozzi, R. P. (2002). Mustering motivation to enact decisions: How decision process characteristics influence goal realization. Journal of Behavioural Decision Making, 15, 167-188.

Doney, P. M. \& Cannon, J. P. (1997). An examination of the nature of trust in buyer-seller relationships. Journal of Marketing, 61, 35-51.

Emmons, R. A., \& McCullough, M. E. (Eds.). (2002). The psychology of gratitude. New York: Oxford University Press.

Ferguson,T. J. (1999). Guilt. In D. Levinson, J. J. Ponzetti, \& P. F. Jorgensen (Eds.) Encyclopaedia of Human Emotions (pp. 307-315). New York: Macmillan.

Fornell, C., \& Larcker, D. (1981). Structural equation models with unobservable variables and measurement error. Journal of Marketing Research, 1, 39-50.

Garbarino, E. \& Johnson, M. S. (1999). The different roles of satisfaction, trust, and commitment in customer relationships. Journal of Marketing, 63, 70-87.

Grégoire, Y., Tripp, T. M., \& Legoux, R. (2009). When customer love turns into lasting hate: the effects of relationship strength and time on customer revenge and avoidance. Journal of Marketing, 73, 18-32.

Hennig-Thurau, T., Groth, M., Paul, M., \& Gremler, D. D. (2006). Are all smiles created equal? How employee customer emotional contagion and emotional labour impact service relationships. Journal of Marketing, 70, 58-73.

Hu, L. T., \& Bentler, P. (1995). Evaluating model fit. In R. H. Hoyle (Ed.) Structural equation modelling: Concepts, issues, and applications. (pp. 76-99). London: Sage. Lazarus, R. (1991). Psychological stress in the workplace. Journal of Social 
Behaviour and Personality, 6, 1-13.

Lerner, J. S., \& Keltner, D. (2000). Beyond valence: Toward a model of emotionspecific influences on judgement and choice. Cognition \& Emotion, 14, 473-493. McFarlin, D. B., \& Sweeney, P. D. (1992). Distributive and procedural justice as predictors of satisfaction with personal and organizational outcomes. Academy of management Journal, 35, 626-637.

Mehrabian, A., \& Russell, J. A. (1974). The basic emotional impact of environments. Perceptual and Motor Skills, 38, 283-301.

Morgan, R., \& Hunt, S. D. (1994). The commitment trust theory of relationship marketing, Journal of Marketing, 58, 20-38.

Ng, B. F., \& Tsang, H. W. (2000). Evaluation of a goal attainment program using the goal attainment scale for psychiatric in-patients in vocational rehabilitation. Work, 14, 209-216.

Novemsky, N., \& Dhar, R. (2005). Goal fulfilment and goal targets in sequential choice. Journal of Consumer Research, 32, 396-404.

Palmatier, R. W., Jarvis, C. B., Bechkoff, J .R., \& Kardes, F. R. (2009). The role of customer gratitude in relationship marketing. Journal of Marketing, 73, 1-18.

Palmatier, R.W., Dant, R., Grewal, D., \& Evans, K. (2006). Factors influencing the effectiveness of relationship marketing: A meta-analysis. Journal of Marketing, 70, 136-153.

Pham, M. T. (1998). Representativeness, relevance, and the use of feelings in decision making. Journal of Consumer Research, 25, 144-159.

Phillips, D. M. \& Baumgartner, H. (2002). The role of consumption emotions in satisfaction response. Journal of Consumer Psychology, 12, 243-252. 
Richetin, J., Perugini, M., Adjali, I. \& Hurling, R. (2008). Comparing leading theoretical models of behavioural predictions and post-behaviour evaluations. Psychology \& Marketing, 25, 1131-1150.

Richins, M. L. (1997). Measuring emotions in the consumption experience. Journal of Consumer Research, 24, 127-146.

Roseman, I. J. (1991). Appraisal determinants of discrete emotions. Cognition and Emotion, 5, 161-200.

Roseman, I J., Antoniou, A. A. \& Jose, P. E. (1996). Appraisal determinants of emotions: Constructing a more accurate and comprehensive theory. Cognition and Emotion, 10, 241-77.

Ruth, J. A., Brunel, F. F., \& Otnes, C. C. (2004). An investigation of the power of emotions in relationship realignment: The gift recipient's perspective. Psychology \& Marketing, 21, 29-52.

Schmader, T., \& Lickel, B. (2006). The approach and avoidance function of guilt and shame emotions: Comparing reactions to self-caused and other-caused wrongdoing. Motivation and Emotion, 30, 42-55.

Shang, J., Reed, A., \& Croson, R. (2008). Identity congruency effects on donations. Journal of Marketing Research, 45, 351-361.

Smith, C. A., \& Ellsworth, P. C. (1985). Patterns of cognitive appraisal in emotion. Journal of Personality and Social Psychology, 48, 813-838.

Soscia, I. (2007). Gratitude, delight, or guilt: the role of consumers' emotions in predicting post consumption behaviours. Psychology \& Marketing, 24, 871-894. Taylor, S. E., \& Pham, L. B. (1996). Mental simulation, motivation, and action. In P. M. Gollwitzer and J. A. Bargh (Eds.) The psychology of action: Linking cognition and motivation to behaviour, New York: Guilford Press. 
Wagner, T., Hennig-Thurau, T., \& Rudolph, T. (2009). Does customer demotion jeopardize loyalty? Journal of Marketing, 73, 69-85.

Yim, C. K.,Tse, D. K. \& Chan, K. W. (2008). Strengthening customer loyalty

through intimacy and passion: Roles of customer firm affection and customer-staff relations in services. Journal of Marketing Research, 45, 741-756.

Yi, S., \& Baumgartner, H. (2004). Coping with negative emotions in purchaserelated situations. Journal of Consumer Psychology, 14, 303-317.

Zhang, Y., Huang, S.C., \& Broniarczyk, S. M. (2010). Counteractive construal in consumer goal pursuit. Journal of Consumer Research, 37, 129-142. 
Figure 1: Hypothesized model to explore relationships between goal attainment, agency of causation and consumption based emotions

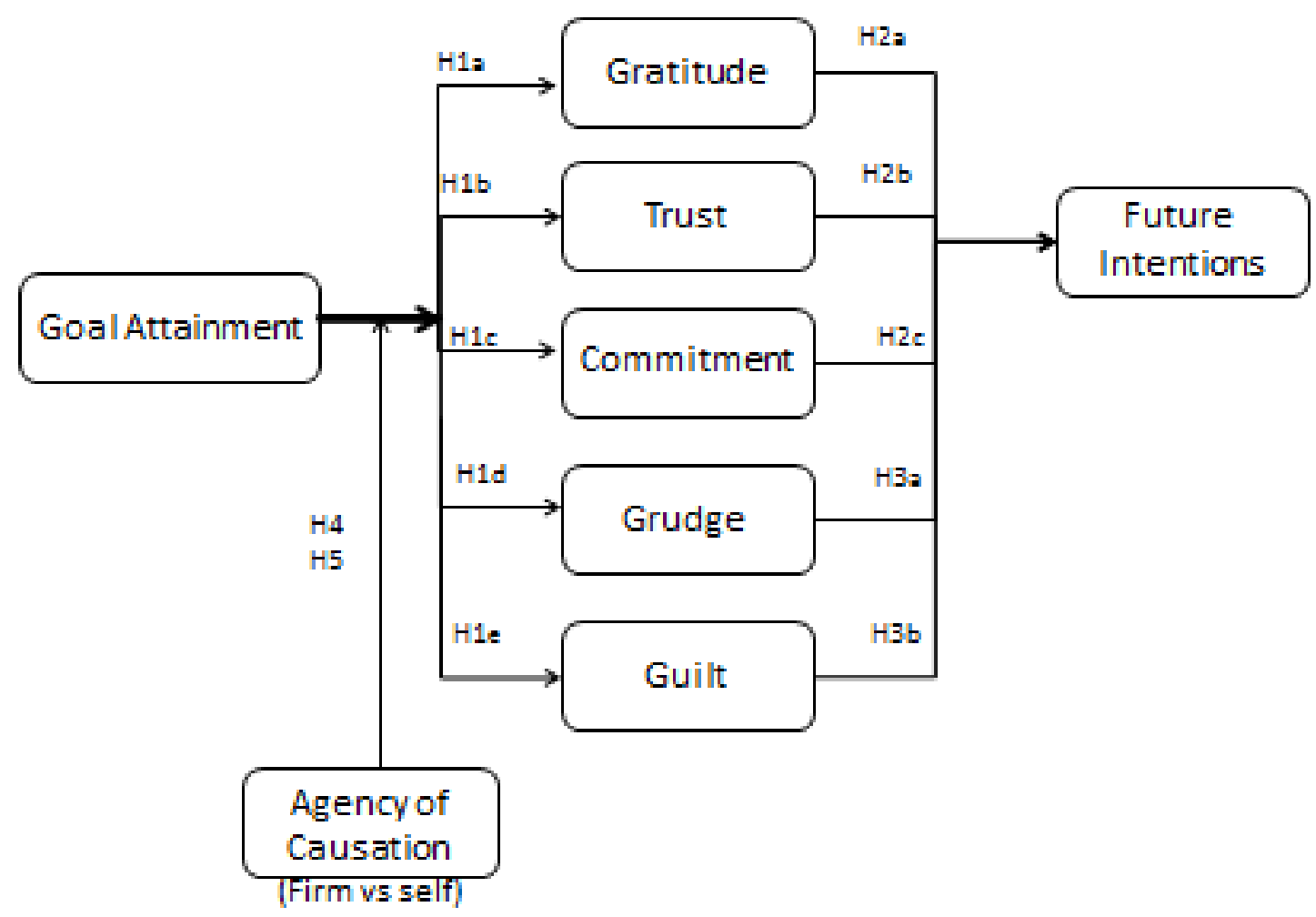


Figure 2: Mean plots for consumption emotions and relational mediators based on varying levels of goal attainment and agency of causation

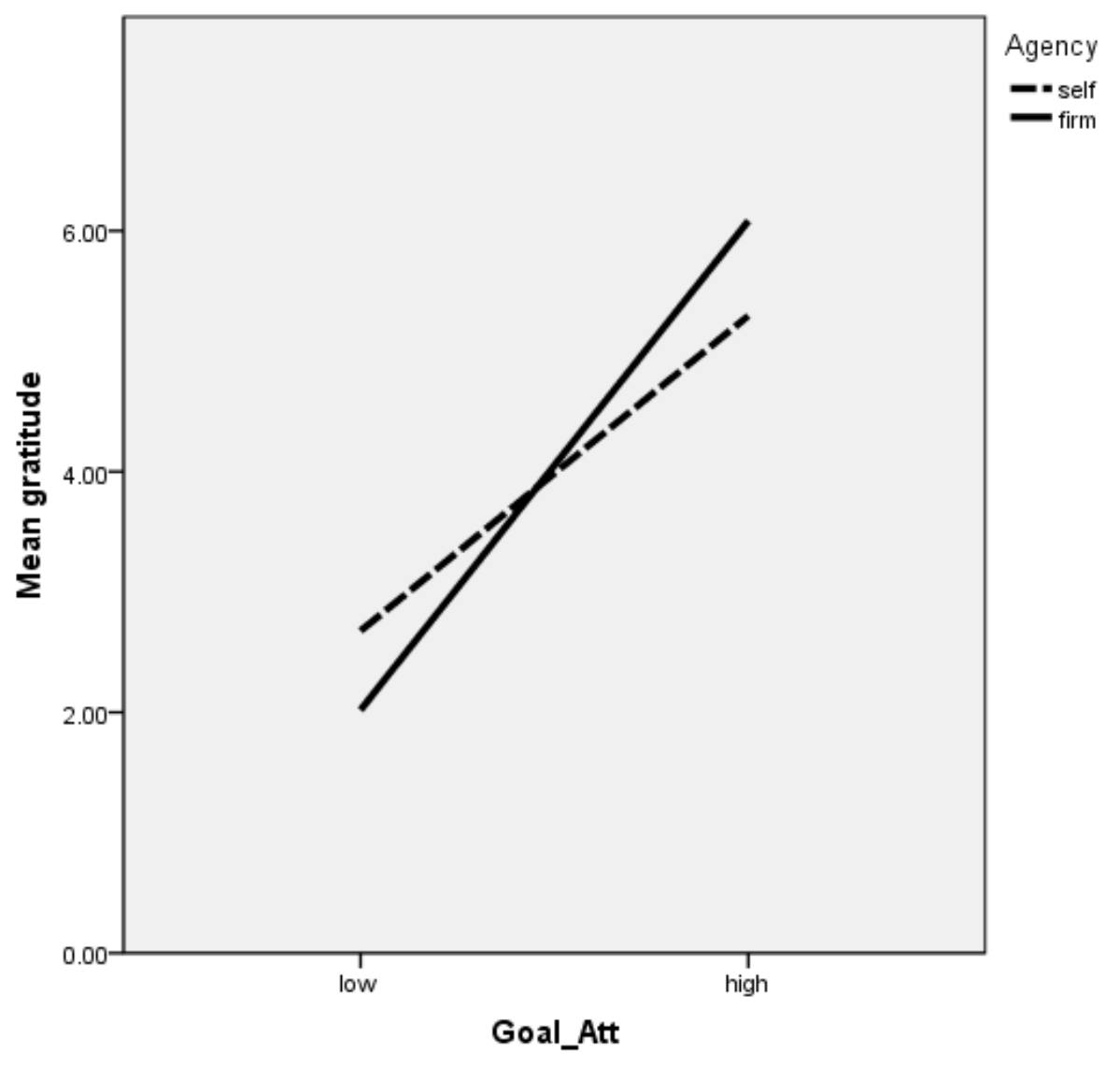



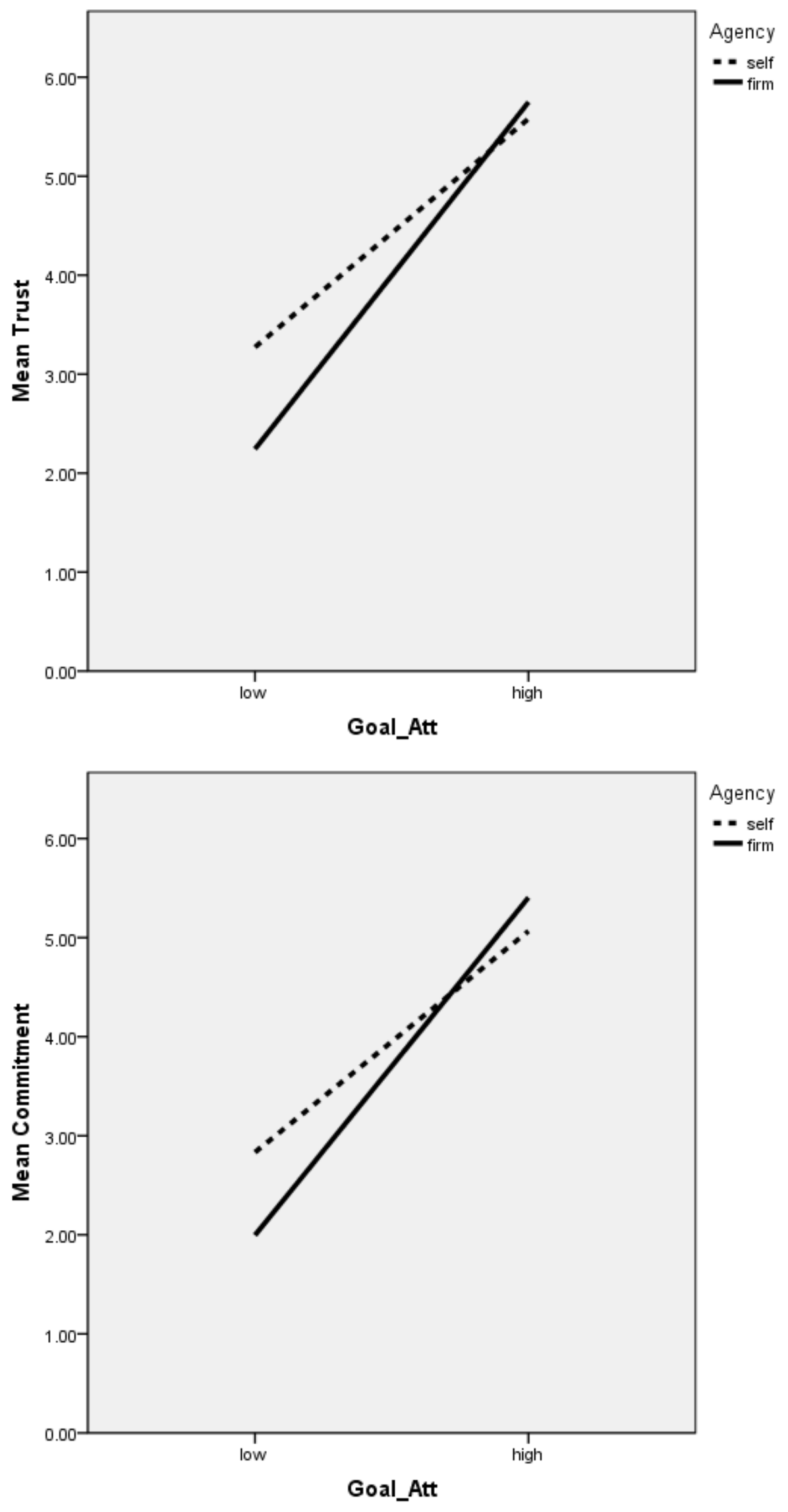

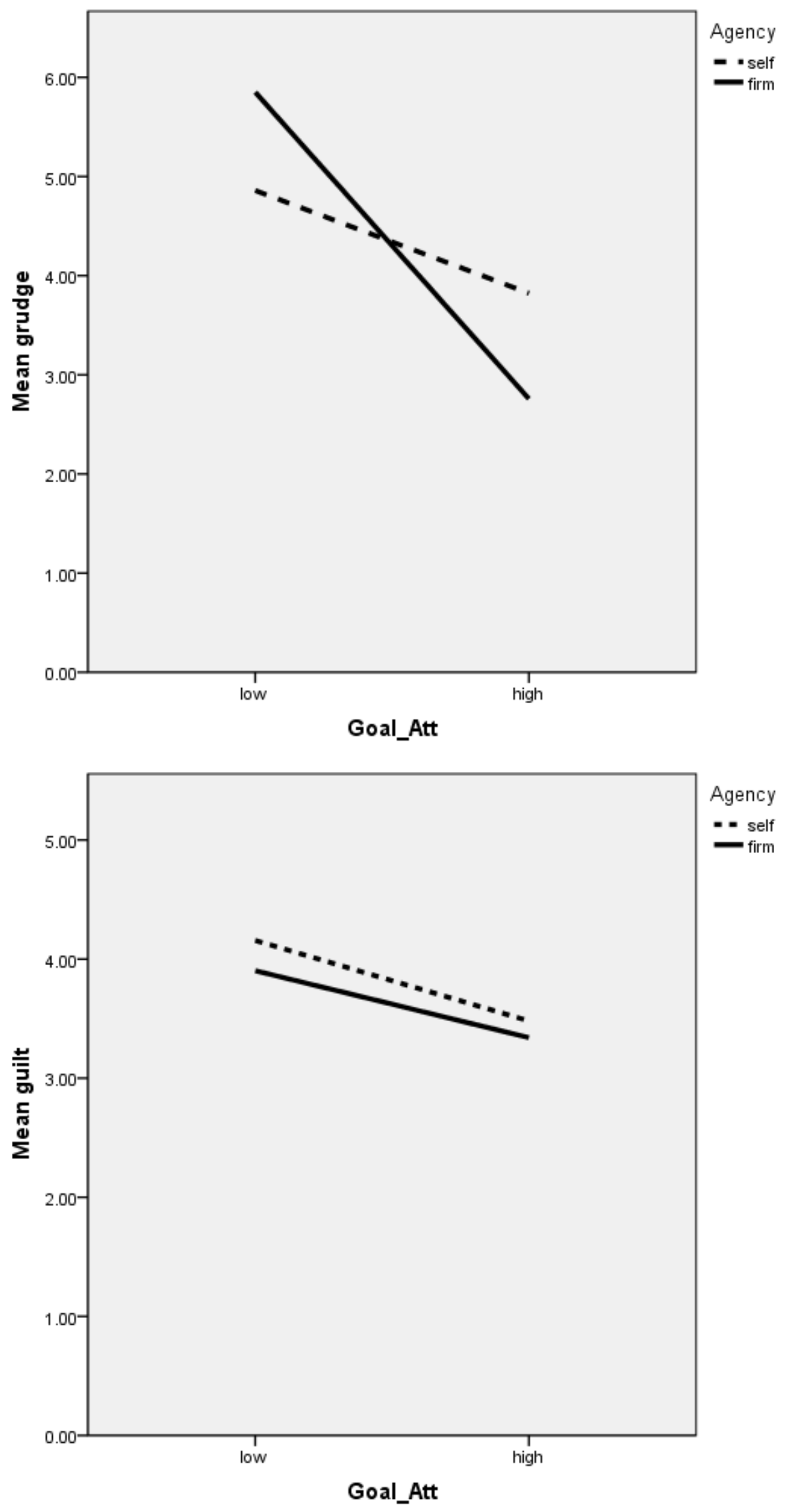
Table 1. Descriptive statistics for constructs after CFA

\begin{tabular}{|c|c|c|c|c|c|c|}
\hline Constructs & Loadings & Mean & $\begin{array}{l}\text { Standard } \\
\text { deviation }\end{array}$ & $\begin{array}{l}\text { Cronbach's } \\
\text { Alpha }\end{array}$ & $\begin{array}{l}\text { Average } \\
\text { Variances } \\
\text { Extracted }\end{array}$ & $\begin{array}{l}\text { Composite } \\
\text { Reliability }\end{array}$ \\
\hline & \multicolumn{3}{|c|}{ Goal attainment (GA) } & .79 & .83 & .91 \\
\hline GA1 & 0.83 & 4.09 & 1.83 & & & \\
\hline GA2 & 0.79 & 4.14 & 1.85 & & & \\
\hline \multicolumn{4}{|c|}{ Gratitude (GRA) } & .98 & .98 & .99 \\
\hline GRA1 & 0.96 & 3.80 & 2.19 & & & \\
\hline GRA2 & 0.99 & 3.86 & 2.18 & & & \\
\hline \multicolumn{4}{|c|}{ Trust (TRU) } & .96 & .96 & .98 \\
\hline TRU1 & 0.98 & 3.86 & 2.15 & & & \\
\hline TRU2 & 0.94 & 3.93 & 2.09 & & & \\
\hline \multicolumn{4}{|c|}{ Commitment (COM) } & .95 & .92 & .97 \\
\hline COM1 & 0.93 & 3.60 & 1.96 & & & \\
\hline COM2 & 0.99 & 3.84 & 2.09 & & & \\
\hline COM3 & 0.89 & 3.65 & 2.05 & & & \\
\hline \multicolumn{4}{|c|}{ Grudge (GRU) } & .93 & .86 & .95 \\
\hline GRU1 & 0.84 & 4.47 & 1.94 & & & \\
\hline GRU2 & 0.89 & 4.08 & 1.96 & & & \\
\hline GRU3 & 0.93 & 4.39 & 2.04 & & & \\
\hline \multicolumn{4}{|c|}{ Guilt (GUI) } & .79 & .71 & .88 \\
\hline GUI1 & 0.64 & 3.18 & 1.79 & & & \\
\hline GUI2 & 0.92 & 3.92 & 1.76 & & & \\
\hline GUI3 & 0.72 & 4.10 & 1.69 & & & \\
\hline \multicolumn{4}{|c|}{ Future intentions (FI) } & .95 & .95 & .98 \\
\hline FI1 & 0.97 & 3.62 & 2.15 & & & \\
\hline FI3 & 0.94 & 3.55 & 2.11 & & & \\
\hline
\end{tabular}


Table 2: Differences in emotions and relational mediators between scenarios

\begin{tabular}{llll}
\hline & & & Agency of causation \\
\hline High goal attainment & Gratitude & Self $(\mathrm{n}=151)$ & Firm $(\mathrm{n}=133)$ \\
& Trust & $5.17(1.33)$ & $6.10(0.96)$ \\
& Commitment & $5.51(1.03)$ & $5.71(1.20)$ \\
& Grudge & $5.07(1.08)$ & $5.41(1.20)$ \\
& Guilt & $3.70(1.83)$ & $2.74(1.45)$ \\
\hline Low goal attainment & Gratitude & $3.48(1.38)$ & $3.34(1.56)$ \\
& Trust & $2.70(1.63)$ & $2.03(1.48)$ \\
& Commitment & $2.95(1.51)$ & $1.97(1.37)$ \\
& Grudge & $2.83(1.53)$ & $1.99(1.34)$ \\
& Guilt & $4.59(1.43)$ & $5.69(1.18)$ \\
\hline
\end{tabular}

Note: mean scores with standard deviation in parentheses 
Table 3: SEM results for hypothesized relationships

\begin{tabular}{|c|c|c|c|}
\hline \multirow[t]{2}{*}{ Relationships } & \multicolumn{2}{|c|}{$\begin{array}{l}\text { Full Model } \\
(\mathrm{N}=284)\end{array}$} & \multirow[t]{2}{*}{ Hypotheses } \\
\hline & $\begin{array}{l}\text { Standardized } \\
\text { parameter } \\
\text { estimate }\end{array}$ & $t$-value & \\
\hline H1a: GA $\rightarrow$ GRA & 0.95 & 12.55 & Support \\
\hline H1b: GA $\rightarrow$ TRU & 0.99 & 13.05 & Support \\
\hline H1c: $\mathrm{GA} \rightarrow \mathrm{COM}$ & 0.92 & 12.06 & Support \\
\hline H1d: GA $\rightarrow$ GRU & -0.67 & -9.11 & Support \\
\hline H1e: GA $\rightarrow$ GUI & -0.13 & -1.96 & Support \\
\hline $\mathrm{H} 2 \mathrm{a}: \mathrm{GRA} \rightarrow \mathrm{FI}$ & 0.13 & 1.57 & Support \\
\hline H2b: TRU $\rightarrow$ FI & 0.29 & 2.76 & Support \\
\hline $\mathrm{H} 2 \mathrm{c}: \mathrm{COM} \rightarrow \mathrm{FI}$ & 0.40 & 5.77 & Support \\
\hline H3a: GRU $\rightarrow$ FI & -0.20 & -5.32 & Support \\
\hline H3b: GUI $\rightarrow$ FI & -0.03 & -1.13 & No support \\
\hline
\end{tabular}

Notes 1: GA: goal attainment, GRA: gratitude, TRU: trust, COM: commitment, GRU: grudge, GUI: guilt, FI: future intentions. 2: Due to insufficient loading of GUI-1 (Table 1), the model was re-run with guilt as a two-item scale but its influence on future intentions was still not significant. 
Table 4: ANOVA results

\begin{tabular}{|c|c|c|c|c|c|c|}
\hline $\begin{array}{c}\text { Dependent } \\
\text { variables }\end{array}$ & $\begin{array}{c}\text { Sources of } \\
\text { variation }\end{array}$ & $\mathrm{df}$ & $\begin{array}{c}\text { Mean } \\
\text { squares }\end{array}$ & $\mathrm{F}$ & significance & Hypotheses \\
\hline \multirow[t]{3}{*}{ Gratitude } & $\begin{array}{c}\text { Goal } \\
\text { attainment } \\
\text { (A) }\end{array}$ & $(1,282)$ & 772.85 & 423.39 & $<0.01$ & \\
\hline & $\begin{array}{c}\text { Agency of } \\
\text { causation } \\
\text { (B) }\end{array}$ & $(1,282)$ & 0.30 & 0.16 & n.s & \\
\hline & A X B & $(1,282)$ & 36.21 & 19.83 & $<0.01$ & $\begin{array}{c}\text { H4a: } \\
\text { support }\end{array}$ \\
\hline \multirow[t]{3}{*}{ Trust } & A & $(1,282)$ & 585.09 & 393.69 & $<0.01$ & \\
\hline & $\mathrm{B}$ & $(1,282)$ & 12.82 & 8.63 & $<0.01$ & \\
\hline & $\mathrm{A} X \mathrm{~B}$ & $(1,282)$ & 24.90 & 16.75 & $<0.01$ & $\begin{array}{c}\text { H4b: } \\
\text { support }\end{array}$ \\
\hline \multirow[t]{3}{*}{ Commitment } & A & $(1,282)$ & 550.98 & 328.13 & $<0.01$ & \\
\hline & B & $(1,282)$ & 4.30 & 2.56 & n.s & \\
\hline & $\mathrm{A} X \mathrm{~B}$ & $(1,282)$ & 23.94 & 14.26 & $<0.01$ & $\begin{array}{l}\mathrm{H} 4 \mathrm{c}: \\
\text { support }\end{array}$ \\
\hline \multirow[t]{3}{*}{ Grudge } & $\mathrm{A}$ & $(1,282)$ & 295.01 & 132.97 & $<0.01$ & \\
\hline & B & $(1,282)$ & 0.09 & 0.04 & n.s & \\
\hline & A X B & $(1,282)$ & 73.97 & 32.98 & $<0.01$ & $\begin{array}{c}\text { H5a: } \\
\text { support }\end{array}$ \\
\hline \multirow[t]{3}{*}{ Guilt } & $\mathrm{A}$ & $(1,282)$ & 26.55 & 12.71 & $<0.01$ & \\
\hline & B & $(1,282)$ & 2.68 & 1.29 & n.s & \\
\hline & A X B & $(1,282)$ & 0.22 & 0.11 & n.s & $\begin{array}{l}\text { H5b: no } \\
\text { support }\end{array}$ \\
\hline
\end{tabular}

